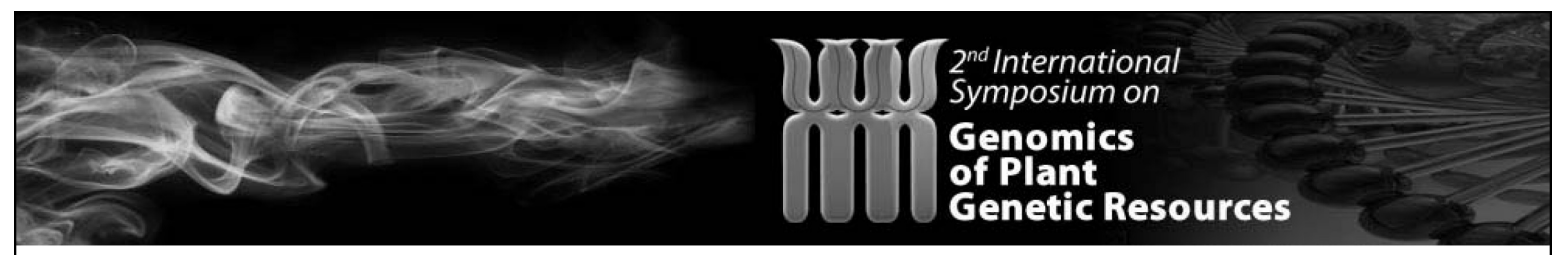

\title{
Genomics of Plant Genetic Resources
}

\author{
24-27 April 2010, Bologna, Italy
}

In recent years, a truly impressive number of advances in genetics and genomics have greatly enhanced our understanding of structural and functional aspects of plant genomes. These advances have led to new and improved screening methods for selecting superior genotypes more efficiently as well as for improving the decision-making process for more efficient breeding strategies. At the same time, the demand for agricultural production has been changed in a dramatic way. World food production is being challenged by global climate change and an ever-increasing demand for food, feed, fibre and biofuel.

Never before has the importance of effectively harnessing the potential of plant biodiversity been more evident and urgent. More importantly, it has been estimated that food production will need to be doubled by 2050 in order to adequately feed mankind. From the recent research experience, it is clear that genomics research on plant genetic resources and genomics-assisted breeding have great potential to revolutionize world agriculture in various ways in both developed and developing countries. As a result, the first symposium of its kind was held in Beijing, China in 2005.

The second symposium of this series is particularly timely considering that 2010 has been declared the "International Year of Biodiversity" by the United Nations. As part of the activities planned for the year, Bioversity International (Rome, Italy), the IPK (Gatersleben, Germany) and the University of Bologna have organized the $2^{\text {nd }}$ International Symposium on "Genomics-based Plant Germplasm Research", to be held in Bologna, Italy. The main theme of this symposium is "Harnessing plant biodiversity for food security and nutritional quality".

Plant Genetic Resources: Characterization and Utilization will publish a special issue that will assemble manuscripts from delegates to the Congress.

We cordially invite you to attend this Congress and look forward to seeing you in Bologna.

The deadline for abstract submission is $\mathbf{3 1}$ January 2010.

For more information about the Congress visit:

www.gpgr2.com 


\section{CAMBRIDGE JULNALS}

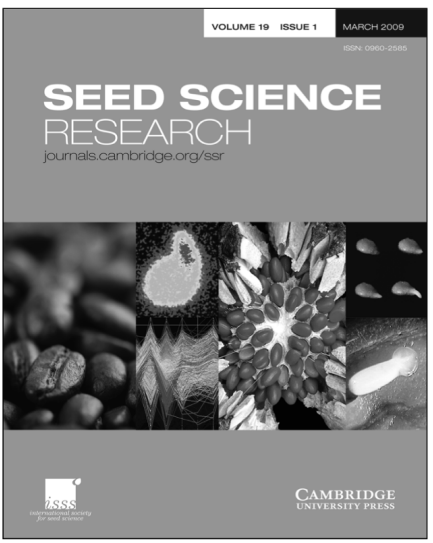

Seed Science Research

is available online at:

http://journals.cambridge.org/ssr

To subscribe contact

Customer Services

in Cambridge:

Phone +44 (0)1223 326070

$\mathrm{Fax}+44(0) 1223325150$

Email journals@cambridge.org

in New York:

Phone +1 (845) 3537500

Fax +1 (845) 3534141

Email

subscriptions_newyork@cambridge.org

\section{SEED SCIENCE RESEARCH}

Published on behalf of the International Society of Seed Science

\section{Editor}

H. W. M. Hilhorst, Wageningen University, The Netherlands

Seed Science Research, the official journal of the International Society for Seed Science, is a leading international journal featuring high-quality original papers and review articles on the fundamental aspects of seed science, reviewed by internationally distinguished editors. The emphasis is on the physiology, biochemistry, molecular biology and ecology of seeds.

\section{Price information is available at:} http://journals.cambridge.org/ssr

\section{Free email alerts}

Keep up-to-date with new material - sign up at http://journals.cambridge.org/alerts 


\section{Notes for Contributors}

\section{Instructions to authors for submission of manuscripts to Plant Genetic Resources: Characterization and Utilization}

\section{Submission}

Manuscripts should be submitted by e-mail, in the form of attachments sent to the journal administrator Faye Kalloniatis (mailto:plantgeneticresources@googlemail.com). Manuscripts must be written in good English in double-spaced 12pt Times New Roman, using a current version of Microsoft Word or OpenOffice.org Writer. Figures and Tables should be included as separate attachments, and not pasted within the body of the text. Material submitted for publication in the print copy of the journal can be supported by supplementary material (figures or tables) which will be published online only. Any supplementary material must be submitted as separate attachment(s), each clearly marked as "supplementary figures" or "supplementary tables".

\section{Peer review process}

All manuscripts are peer reviewed by two referees, who may or may not choose to remain anonymous. The journal makes every effort to complete the peer review process as quickly as possible, and generally this is achieved within 6 weeks of receipt of the manuscript. Articles which the editor considers may be accepted subject to modification must be resubmitted to the journal within 1 month of their return date in order to be considered part of the original submission. If this deadline is passed, a resubmission will be considered as a new manuscript. If authors choose to resubmit, they must provide, in a covering letter, a detailed point-by-point response to all the criticisms raised by each of the reviewers, and where appropriate, those raised by the editor.

\section{Copyright}

The journal needs your agreement to publish your article and you will be sent a 'Transfer to copyright' form along with your first set of proofs. The form must be completed and returned to Cambridge University Press.

\section{Types of article}

The journal accepts two forms of research report - full articles and short communications. The format of these is detailed separately below. Authors should note that the journal will not review submissions using the RAPD marker system, except where very large numbers of assays place a cost limitation on the analysis, or where RAPD data is combined with, and is co-analysed with other forms of descriptive data, which allows an objective means of assessing the credibility of the RAPDs.

\section{Full articles}

The title page should carry the title of the article and the authors' names and addresses. Also indicate the name and include the e-mail address of the corresponding author. The e-mail address is particularly important as page proofs will be sent electronically as a .pdf file to the corresponding author for checking. (See 'page proofs' section below).

The text must be divided into sections, each beginning on a new page. The sections consist of Abstract, Introduction, Materials and Methods, Results, Discussion, Acknowledgements, References, Tables, Figure legends. In exceptional circumstances, the Results and Discussion sections can be combined, but where this has been done, the authors must provide a justification for doing so in their covering letter. The Abstract should not normally consist of more than 200 words, and in no case should exceed 300 words. It should indicate the scope and main conclusions of the paper. Below the text, add a list of keywords for indexing purposes.

The Introduction should be no more than 750 words long. It should explain why the work was done, and briefly introduce the scope and contents of the paper.

The Materials and Methods section should detail experimental design and statistical analysis and should be kept as brief as possible with the aid of appropriate citation to the literature (e.g. for standard methods etc.).

Results should be recorded in the past tense.
The Discussion should interpret the results, and present them in the broader context of other work on the subject. It should not simply be a restatement of the results.

Citations within the text should be listed in chronological order, by author and date, using 'and' between names of joint authors and, for those with more than two authors, citing only the first author et al. (e.g. White et al., 1993). The final list of references should be in the following format, and listed by alphabetical order of author, e.g.

Gregory RS (1985) Triticale breeding. In: Lupton FGH (ed.) Wheat Breeding: Its Scientific Basis. London: Chapman and Hall, pp. 20-30.

Kingston-Smith AH, Bollard AL, Humphreys MO and Theodorou MK (2002) An assessment of the ability of the stay-green phenotype in Lolium species to provide an improved protein supply for ruminants. Annals of Botany 89: 731-740.

Marshall DR and Brown AHD (1973) Stability of performance mixtures and multilines. Euphytica 22: 405-412.

Smith JE (1988) The effects of roguing on the frequency of atypical winter wheat plants. PhD Thesis, University of Nottingham.

Tables should be numbered consecutively (Table 1, Table 2 ..., NOT Table 1a, 1b, etc). Each should be headed by a caption worded in a way which makes it self-explanatory. Tables intended for the print copy must be no larger than one A4 page in portrait typed in $12 \mathrm{pt}$ font. These restrictions do not apply to tables presented as online supplementary material. The number of tables in the print copy is limited to four. All tables (both print copy and online supplementary) should be prepared as text files (MS Word or similar), and not as spreadsheets (MS Excel or similar). Supplementary tables must be labelled consecutively Table S1, Table S2 etc.

Figures must be submitted as jpeg files (not powerpoint). The size of the file containing all the figures intended for the print copy should not exceed $2 \mathrm{Mb}$. The number of figures is limited to four per article. Authors will be asked to make a financial contribution towards the cost of printing colour illustrations. Additional figures can be published as online supplementary material, and these should be clearly labelled and referred to in the text as Figure S1, Figure S2, etc. No cost recovery is expected for online colour illustrations.

Note that the total number of tables plus figures appearing in the print copy may not exceed six.

Please indicate the optimum placement of all tables and figures within the text.

Both the Figures and the Tables should be organized into a separate file. All supplementary material must also be presented within separate file(s) (Supplementary Tables and/or Supplementary Figures).

\section{Short communications}

These will be limited to a maximum of 1000 words of text, plus two figures or tables (or one of each). Section headings should normally be restricted to Abstract, Experimental, Discussion, Acknowledgements, References. This form of communication has been explicitly designed to reflect the format of poster presentations.

\section{Page proofs}

Once typeset, the corresponding author will receive page proofs by e-mail as a .pdf file. You will be asked to return the corrections via email (no later than 4 days after receipt). There is also a copyright transfer form in the file; this needs to be signed and returned along with the offprint order.

\section{Offprints}

With the .pdf proof, the corresponding author will also be e-mailed an offprint order form. If offprints of the paper are required, the appropriate form should be completed, using the price scale provided, and returned with the corrected proof to the proofreader. You will be provided with a final pdf file by e-mail at no expense. You will also be sent a 'Terms and Conditions' form which outlines how you may use your .pdf file.

Last updated June 2009 


\section{Plant Genetic Resources Characterization and Utilization}

\section{Contents}

Response of early maturing maize landraces and improved varieties to moisture deficit and sufficient water supply Abebe Menkir, Baffour Badu-Apraku, Sam Ajala, Alpha Kamara and Abdou Ndiaye . . . . 205

Genetic diversity among Lagenaria siceraria accessions containing resistance to root-knot nematodes, whiteflies, ZYMV or powdery mildew

Amnon Levi, Judy Thies, Kai-shu Ling, Alvin M. Simmons, Chandrasekar Kousik and

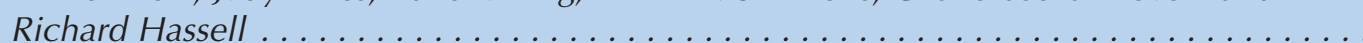

Short Communication

Evaluation of USDA Lupinus sp. collection for seed-borne potyviruses

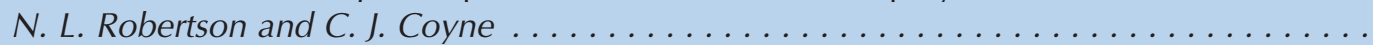

Genetic diversity and phaseolin variation in Portuguese common bean landraces

G. Igrejas, V. Carnide, P. Pereira, F. Mesquita and H. Guedes-Pinto . . . . . . . . . . . .

Evaluation of the grain methionine, lysine and tryptophan contents of maize (Zea mays L.)

germplasm in the Germplasm Enhancement of Maize Project

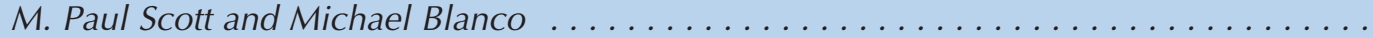

Genetic analysis of mango landraces from Mexico based on molecular markers

Didiana Gálvez-López, Sanjuana Hernández-Delgado, Maurilio González-Paz,

Enrique Noe Becerra-Leor, Miguel Salvador-Figueroa and Netzahualcoyotl Mayek-Pérez . . .

Hexacosanoic acid and other very long-chain fatty acids in peanut seed oil

Lisa L. Dean and Timothy H. Sanders . . . . . . . . . . . . . . . . . . . . . . . .

Characterization of medicinal Senna genetic resources

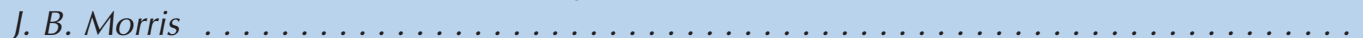

Classification and diversity of sacred and American Nelumbo species: the genetic relationships of flowering lotus cultivars in Japan using SSR markers

Nakao Kubo, Masashi Hirai, Akio Kaneko, Daizo Tanaka and Kumaji Kasumi . . . . . . . . . .

Development and characterization of Triticum aestivum-Aegilops kotschyi amphiploids with high grain iron and zinc contents

Nidhi Rawat, Vijay K. Tiwari, Kumari Neelam, Gursharn S. Randhawa, Parveen Chhuneja, Kuldeep Singh and Harcharan S. Dhaliwal . . . . . . . . . . . . . . . . . . . . .

Genetic relatedness and cultivar identification in a valuable garden species,

Hesperantha coccinea (Schizostylis coccinea)

Kirsten Wolff, Sabina Knees and Suzanne Cubey

Phenotypic and molecular diversity among landraces of snapmelon (Cucumis melo var. momordica) adapted to the hot and humid tropics of eastern India

N. P. S. Dhillon, Jugpreet Singh, Mohamed Fergany, Antonio J. Monforte and A. K. Sureja .. 